\title{
Secondary School Teachers' Conceptions and Their Teaching Practices using Graphing Calculators
}

\author{
by
}

\author{
Jane A. Lee \\ Earl Haig Secondary School, Toronto, Ontario \\ Douglas E. McDougall \\ Ontario Institute for Studies in Education, University of Toronto, Toronto, Ontario
}

Corresponding author: Douglas E. McDougall, OISE/UT, 252 Bloor Street West, Toronto, Ontario, M5S 1V6, doug.mcdougall@utoronto.ca

Keywords: Graphing calculators, secondary school mathematics, conceptions of mathematics, mathematics teachers. 


\begin{abstract}
This paper investigates secondary school teachers' conceptions of mathematics and their teaching practices in the use of graphing calculators in their mathematics classrooms. Case studies on three teacher participants were developed using quantitative and qualitative data that consisted of self-assessments on beliefs in mathematics, observations, surveys on professional and personal technology use, and semi-structured interviews.

All three teachers had a similar goal of attempting to use the graphing calculators to eliminate mechanical processing time and enhance their students' ability to construct their own learning. The major findings of this paper relate to: (1) proficiency with the graphing calculator; (2) a common starting point; and (3) integration into the curriculum. The paper concludes that factors such as teachers' personal experiences and teaching practices, together with the level of proficiency of the students with the technology, influence how the graphing calculators are used in the mathematics classroom. When graphing calculators are used effectively in the mathematics classroom, they are a powerful tool to assist teachers in providing their students with an environment to help them construct their mathematical knowledge and understanding.
\end{abstract}




\section{Introduction}

Principles and Standards for School Mathematics (NCTM, 2000) has six basic principles that the NCTM suggests educators use to establish a foundation for mathematics programs. Technology is the focus for one of these six principles: "Technology is essential in teaching and learning mathematics; it influences the mathematics that is taught and enhances students' learning" (National Council of Teachers of Mathematics, 2000, p. 25).

There is a growing body of literature that confirms that mathematics teachers are trying to incorporate technology in their classrooms in the ways suggested by NCTM (2000). The teacher's role is more important than ever in order for students to progress in the areas that will help them develop a relational understanding of mathematics with the use of technology (Skemp, 1978). Yet many teachers have resisted implementing technology into their curriculum because they feel that the new technology will interfere with their role as teacher. The literature suggests that teachers feel a loss of control over their teaching practices once technology is introduced into the classroom (Dunham \& Dick, 1994; McDougall, 1997). However, a growing body of knowledge is suggesting that a teacher's role in the classroom is not diminished by the use of technology. In order for students to reap the benefits that technology offers, the teacher must play an even more important role.

Instead of worrying about what the calculators can do, teachers need to explore what more students can do by using the calculators. Students can use graphing calculators as "tools to use numeric and graphic strategies in addition to the traditional paper-and-pencil algebraic techniques" (Dunham \& Dick, 1994, p. 441). By using calculators as a tool to perform the 
functions listed above, students no longer have to spend time learning to do what a machine can do more efficiently and effectively.

Once exposed to the capabilities of technology, most teachers recognize that software programs and graphing calculators have the potential to be powerful tools for the mathematics classroom. However, although most teachers can accept the additional possibilities that come with the integration of technology in their mathematics program, many teachers still hold back from using it.

Studies have shown that teachers who use technology for their personal use are more comfortable using technology in their classrooms (Cradler, Freeman, Cradler, \& McNabb, 2002; Moersch, 2002). However, in order to take full advantage of the technology available to them, teachers need guidance and support from as many resources as possible. Research has shown that teachers would be more willing and have a more positive attitude towards incorporating technology into their teaching practices if they were given time to pursue professional development in the area (Arbaugh, 2003; Cradler et al., 2002). Teachers must have resources such as access to supplementary teaching materials, being provided with release time from regular teaching duties to attend workshops or conferences, or having the opportunity to join a group of teachers who are willing to share and exchange ideas with each other.

It is still unclear whether teachers are integrating the use of technology simply because it is mandated or because they understand the role it can play in aiding student understanding. The current literature has only explored to a limited extent how teachers' conceptions of mathematics influence their use of technology in the classroom. While the literature supports the idea that it is imperative that teachers help guide students' conceptual understanding, there is little known 
about how a teacher's conceptions of mathematics translates to his or her instructional practices involving the use of technology.

This paper reports on a study that explored how a teacher's conception of mathematics instruction impacts his or her use of technology in the classroom in an attempt to determine whether teachers are harnessing the capabilities of technology. The study addressed this problem by describing and analyzing experiences of three mathematics teachers as they implement the mathematics curriculum using the graphing calculator. Responses from a self-assessment, a survey and a questionnaire helped develop an understanding of the teachers' beliefs and knowledge of mathematics. The teachers were observed in their classrooms to examine how their conceptions of mathematics translate into their teaching practices.

Graphing calculators began to appear on the education scene in the mid 1980s, approximately ten years after scientific calculators were introduced to the mathematics classroom. Since then, numerous research studies have been conducted on student learning and performance with the graphing calculator. There have been reports where the graphing calculator has made no difference on student performance (Graham, Headlam, Honey, Sharp, \& Smith, 2003). However, the majority of research on student use of graphing calculators has been shown to have a positive impact on student learning and performance.

Through use of the graphing calculator, studies have demonstrated better student achievement with procedural knowledge (Doerr \& Zangor, 2000; Forster, Mueller, Haimes, \& Malone, 2003), provided opportunities allowing students to connect procedural knowledge with conceptual understanding (Graham, 1999; Iossif, 1999; Quesada \& Maxwell, 1994) and contributed to increasing a deeper conceptual understanding and solving more complex problems 
(Cates, 2002; Drier et al., 1999; Drijvers \& Doorman, 1996; Dunham \& Dick, 1994; Ferrucci \& Carter, 2003; Forster et al., 2003).

While there is a large body of research that illustrates positive findings for student learning and performance when graphing calculators are used in the mathematics classroom, there is only limited information as to how and why these outcomes are achieved. There is no guarantee that students will take advantage of the technology that they have at hand (Graham et al, 2003). Even though these students had graphing calculators, they were at best labeled "quasiproficient" at using them, as they were using their graphing calculators in a similar way to how they would use a scientific calculator. The mere presence of technology such as graphing calculators in the classroom does not mean that there will be an automatic enhancement of student learning (Dunham \& Dick, 1994).

The introduction of graphing calculators in the classroom emphasizes the role of the teacher. In order to understand the teaching practices of a teacher using the graphing calculator, we must first understand that teacher's conceptions of teaching with technology. By determining how a teacher perceives the role of technology in the classroom, we will begin to understand the instruction that students are receiving to aid them in their learning and performance with these tools.

A 2001 study asked 21 elementary school teachers to complete a questionnaire on their "beliefs about mathematics and teaching" and these beliefs were matched up to classroom observations (Stipek, Givvin, Salmon, \& MacGyvers, 2001). The study examined teacher beliefs and practices that were directly related to inquiry-oriented (constructivist or social-constructivist) mathematics instruction. In inquiry-oriented practices, the "role of the teacher is to support and 
guide this constructive process rather than to transmit discrete knowledge" (p. 214). Stipek et al. found that more traditional beliefs were associated with more traditional practices.

An earlier study showed that there was a direct correlation between how teachers themselves learned mathematics and how they believed mathematics should be taught (Philipp, Flores, Showder, \& Schappelle, 1994). The four teachers involved in this study were labeled "extraordinary" teachers because these teachers did not have a traditional view of mathematical authority in the classroom. Although the teachers had varied backgrounds, they shared the same perspective of "accompanying the view that teaching mathematics involves the development of conceptual understanding is the belief that students do not learn simply by being told" (p. 169). The commonalities that these teachers shared were their depth of commitment to teaching, the degree of personal ownership they held for what they reported as change within their classrooms, and the high degree of reflectiveness they exhibited in all their interactions with the researchers.

\section{Method}

Both qualitative and quantitative data was collected for the three case studies that formulate this collective case study. Four types of data were collected from the three teacher participants: a self-assessment on beliefs about mathematics; classroom observations; a survey on technology use; and interviews.

Each of the three teacher participants completed the self-assessment prior to the classroom observations. The 24 questions in the self-assessment came from the teacher's version of a Conceptions of Mathematics Inventory (Grouws, 1996). The 24 questions chosen from the inventory specifically were divided up into three groups that looked at three different conceptions of mathematical knowledge: the status of Mathematical Knowledge; doing Mathematics; and learning Mathematics. The responses of the three teacher participants were 
categorized and a score was given to each of the three teacher participants for each of the three conceptions.

During each classroom observation session, direct quotes and the interactions between teacher and class and between student and student were recorded. Observation days were prearranged with the teachers on days when technology was scheduled to be incorporated in the lesson.

Each of the three teacher participants completed the survey prior to the classroom observations. There were 18 questions on the survey on professional and personal technology use. The first 12 questions are rated on a 1 to 6 point scale and were designed to quantitatively measure a teacher's professional and personal technology use. The remaining six questions were designed to give an overall qualitative picture of a teacher's professional and personal use of technology.

Each of the three teachers participated in an interview after her classroom observations were completed. There were 16 semi-structured interview questions, including both closed- and open-ended questions, intended to provide a detailed overview of each teacher's background, qualifications and experience.

\subsection{Participants}

Fifteen intermediate and secondary school mathematics departments were contacted and informed that a study was being conducted working with teachers who had access to classroom sets of graphing calculators. Out of the fifteen mathematics departments, three teachers were selected from three schools that showed interest in this type of study and whose timetables facilitated the data collection timeline. The three teachers volunteered to work on the project and 
the study gained access to these teachers through the District School Board Research and Information Services as well as through the principals of each of the three schools.

\subsection{Data Collection}

The collection of data was ongoing throughout the study. The self-assessment and the survey were collected from the participants before the classroom observations were completed. The teachers were observed in their classrooms and in informal meetings before and after their classes. The classroom observations were recorded in hand-written field notes and then transcribed. The teacher participants reviewed the transcriptions for accuracy. Particular attention and focus during the classroom observations was paid to the dialogue between the teachers and their students, especially the instructions and questions the teachers posed to their students. The teachers were observed in their classrooms a minimum of four times to a maximum of thirteen times during the study. A classroom observation session lasted anywhere from 45 minutes to 75 minutes, depending on the length of the period for that particular day. The semi-structured interview questions were asked once the classroom observations were completed.

\subsection{Data Analysis}

Both quantitative and qualitative data were collected on the three teacher participants. The self-assessment on beliefs in mathematics provided quantitative data. The survey on professional and personal technology use and the classroom observations provided both quantitative and qualitative data. The semi-structured interview questions provided personal, qualitative data on the background and experience of each of the teacher participants.

A computer program, called N6 (QSR, 2002), was used to assemble and manage the qualitative documents and notes, create and manage codes for thinking about the data, index segments of the data, and to search for words and phrases in the text of the documents. The 
program was used for the management and reorganization of the data to preserve the systematic and disciplined nature of the data sorting process. The self-assessment and the survey results gave values that were analyzed to understand the participants' conceptions of mathematics. These values were compared with the classroom observations and semi-structured interview questions to determine how the teachers' conceptions of mathematics influenced their teaching practices. The four types of data were collected and analyzed on the three teacher participants to determine connections that helped answer the study question.

\section{Findings}

These case studies record the teachers' experiences as they deliver the mathematics curriculum with the aid of graphing calculators. Within each case, there is a description of the school, background information about the teacher, a description of the teacher's teaching practices, and an illustration of how each teacher uses the graphing calculator to help deliver her lessons.

\subsection{Victoria}

Victoria teaches in a Secondary School that is situated in a large metropolitan city in Canada. The school is comprised of students in grades 9 through 12 and has a student body of approximately 1200 people. When Victoria was transferred to this school four years ago, she came in as the Department Head of Mathematics. Since joining this school, Victoria has taught the International Baccalaureate (IB) program in the Mathematics Department.

The IB program mandates the use of graphing calculators and hence all the students enrolled in the IB program are required to either purchase their own TI-83 graphing calculators or rent one from the school. Victoria expects her IB students to be proficient at using the graphing calculator. Victoria never uses the viewing screen to demonstrate how her students 
need to reach a solution because she expects her students to be proficient at reaching the solution. Victoria does not give explicit instructions as to which buttons need to be pressed in order to execute a specific function on the graphing calculator. Instead, her instructions to her students when the graphing calculators are used are about the mathematical concepts she wants her students to explore.

Victoria's instructions to her students are based on the mathematical concept she wants her students to investigate and not on how they need to get there. There are times when Victoria has to remind her students to pay attention to their Window settings in order to work with the necessary domain and range. However she will not give them the Window settings and expects her students to discover these values during their own investigations with their graphing calculators.

Victoria expects her students to use their graphing calculators using the honour system. Students cannot use the graphing calculator to sketch a function prior to handing in their quiz papers, but they are allowed to use the graphing calculators to check their answers. Victoria wants to ensure her students know how to do the mathematics operations using paper and pencil methods, before relying on the graphing calculator to show them a solution. Victoria realized that, in order to avoid having her students become dependent on their graphing calculators, she needed to ensure that her students were thinking about what they were doing by requiring them to be ready to support their solutions without the aid of a graphing calculator.

Victoria stresses to her students the importance of expressing mathematical concepts in mathematical notation as well as in language notation. Along with the ability to communicate their understanding in multiple forms, Victoria reiterates to her students the importance of process along with the correct solution, "It's not just good enough to get the right answer. The 
process is important. The next test, I will take off marks if the process is not there." Victoria knows that she needs to remind her students that, although emphasis may be placed on using the graphing calculator to help with the process of understanding mathematics, technology is still only a tool to be used to help with the understanding of mathematics concepts.

Once students are familiar with the operations needed to use their graphing calculators, Victoria knows the graphing calculator can be used to save time on the calculations of a mathematical problem - time that can be allocated to constructing the students' knowledge to understand the problem. On the topic of Optimization, the most difficult step in the process is setting up the maximizing or minimizing equation, because the dependent variable needs to be represented with respect to one independent variable. Determining the equation of constraint to help isolate the independent variable can be challenging, especially if a diagram needs to be drawn that will represent a particular relationship.

Victoria gave her students time to construct their knowledge of how the particular problem needed to be set up. After her students determined the equation of constraint and came up with the maximizing equation, Victoria was able to save her class some time by having her students graph the equation and use the Trace function to locate the maximum value. If Victoria's students wanted to find the maximum value by pencil and paper methods, they would have to calculate the first derivative, set the first derivative to zero and then solve for the independent variable, which would have taken much longer than using the graphing calculator.

Victoria prefers that her students conceptualize mathematical ideas on their own before turning to their peers. However, Victoria has her students work in small groups so that they learn to collaborate and use mathematical language to communicate their thoughts to others. Students are allowed to help construct each other's knowledge of the mathematical ideas behind the 
assignment. For example, students were paired up to complete a graphical Exponential and Logarithmic assignment. When asked how she formed the pairs, Victoria commented that she did not believe in pairing the weakest students with the strongest ones. Instead, Victoria links up students that are similar in ability so that they can learn from each other at the same rate.

Victoria knows that, when her students work in pairs or small groups, dialogue on mathematical procedure is bound to occur because the students will need to discuss alternative strategies given that more than one person is involved in coming up with the solution. In one lesson, Victoria asks her students to graph a specific function. Some of her students proceed to work on the question using the graphing calculator and some are doing the question by hand. Victoria circulates around the room, observing the strategies used by several different students. Victoria comes back to the front of the room and comments, "I am going to use Student A's method [to show you the solution]. But don't erase anything. You can use whatever method you want". In this particular case, Victoria is referring to taking the derivative. While everyone should get the answer for the first derivative, the method they use can vary. Some students may have opted to use the Product Rule and some students may have rearranged the function so that they needed to use the Chain Rule. Victoria supported the notion that her students did not have to rely on any one specific method to reach their solution and could

\subsection{Dawn}

Dawn teaches in a Junior High School that is situated in a large metropolitan city in Canada. The school is comprised of students in grades 7, 8 and 9 and has a student body of approximately 450 people. The school has a staff of about 25 teachers, and including Dawn, the Mathematics department has two full-time math teachers and three part-time Mathematics teachers. 
On average, Dawn allocates 14 days throughout the school year to incorporate the use of technology in her lesson planning for grade 9. The most frequent type of instruction Dawn uses when working with the graphing calculator is how her students can troubleshoot difficulties they encounter. One of the most frequent troubleshooting instructions that Dawn delivers to her students is how to enter the correct Window settings for the graph they are investigating

Dawn appreciates her students' enthusiasm towards using technology when she shows them the capabilities of graphing calculators. Whenever Dawn uses the graphing calculators with her students, she has the viewing screen set up in the front of the classroom so that her students can see exactly what she is doing and so that they can also follow along with their graphing calculators. Although she believes that the positive outcomes from using the graphing calculator outweigh the negative ones, Dawn still becomes frustrated with factors she cannot control. Dawn mentions that the 50-minute class periods used in her school are a significant draw back when trying to use technology in the classroom. Dawn also notes that, even when she plans a lesson using the graphing calculators for a 50-minute class, sometimes a change in the school schedule reduces class time to even less time.

Another factor that Dawn has discovered is beyond her control is that the use of graphing calculators is not always supported in situations outside her classroom. For example, Dawn was really disappointed when she learned that there were no graphing calculator questions for her students to answer on the Education and Quality Assessment Organization (EQAO) test for grade 9 students, even though she had been teaching her students to be prepared for such questions. Dawn is disappointed when her students return from a visit to the grade 10 classrooms as the students mention that they never use graphing calculators in the classroom. 
When Dawn teaches with the graphing calculator, she creates an environment in her classroom where constructivist-learning opportunities are possible. In the following example, two students approach Dawn, each with the same equation inputted in his graphing calculator but apparently with different graphs sketched on the screens:

Student: We used the same equation, but we're getting different graphs. [Several students cluster around two of their peers that have asked the teacher for help on the above question.]

Dawn: It's your Window. We are seeing only part of your graph, which is why it's like a straight line. But we're seeing his entire graph, which is why it looks curved.

Dawn was able to take this opportunity where two students were using different Window settings to sketch the same equation to illustrate that how one sees a graph depends on the viewers' perspective. When the student had a larger Window to work with, he was able to see the entire graph and hence he saw a curved sketch. However, since his partner was working with a smaller Window, he only got to see a part of the sketch, which made him believe he was looking at a line instead of part of a curve. Dawn was able to use this opportunity to express how important it is to agree on established minimum and maximum values for the $\mathrm{x}$ - and $\mathrm{y}$-axes in order to discuss results that would be comparable to each other's answers.

Dawn's students used the graphing calculators to graph linear equations. However, when her students try to graph the equations recommended by one of their peers, nothing appears on their view screens, except the x- and y-axes showing four empty quadrants. Dawn then asks her class, "If you graphed it by hand, what would you do? What would be along our x-axis?" At this point, Dawn begins a discussion with the class in terms of using common sense when graphing a real situation, whether they would really have to have axes that showed negative people or negative amounts of money. The students come to the conclusion that they would only need to 
work in Quadrant one. Dawn explains that each tic on the x-axis represents one person and each tic on the y-axis represents one dollar.

After changing the Window setting to show more appropriate values, and then sketching the two linear equations, Dawn uses the opportunity to remind the students that they are in charge of what is shown on the graphing calculator and that, in the end, the graphing calculator is a tool that is as only useful as the person who optimizes its use. Dawn then begins a discussion with her class as to the reasons why she selected these specific Window settings. While her students could have been left satisfied with the reason, "I have a lot of practice with these" from their teacher, Dawn wants her students to go through the reasoning process themselves of why are appropriate values to use.

Dawn uses the graphing calculator to help her students learn math concepts constructively. Dawn's main point of one lesson was for her students to understand the differences between linear and non-linear equations. Dawn wanted to show her students three different methods for graphing a line so that they can determine the characteristics that distinguish linear from non-linear equations. The first method Dawn uses is through a table of values and the differences between the y-values. The second method Dawn uses is graphing, where she has her students use the graphing calculator to graph the equations that produced the tables of values. For the third method, Dawn has her students work with each of the equations written on the board and lets them determine whether the equation should be gathered under the title "Linear" or "Non-Linear".

The graphing calculator is a tool that Dawn had her students use to sketch and group equations that displayed similar characteristics. The sketches helped her students construct their own understanding of what constitutes a linear equation from a non-linear equation. By 
providing her students with a variety of methods, Dawn was able to help her students consolidate their knowledge of linear equations.

\subsection{Clare}

Clare teaches in a Secondary School that is situated in a large metropolitan city in Canada. The school is comprised of students in grades 9 through 12 and has a diverse student body of approximately 1,500 people. Clare has a deep understanding of mathematics and an indepth knowledge of using the graphing calculator. Clare is very adept at using the graphing calculator and she knows how to troubleshoot technical difficulties that arise when her students are working with the graphing calculators. Clare has been using the graphing calculator in her mathematics classes for all of the seven years she has been teaching. Depending on the mathematics course, Clare uses the graphing calculator approximately 10 to 20 days, in a semester system that offers 91 instructional days in total.

When Clare decides to incorporate the graphing calculator into her mathematics lessons, she ensures certain procedural routines are in place. Clare always has her view screen set up with her graphing calculator screen projected in front of the classroom so that her students are able to follow along with her instructions. When all of the students have a graphing calculator in front of them, Clare is ready to ensure they all begin at the same point.

Although the graphing calculator has all the same capabilities as a scientific calculator, the whole rationale behind using the graphing calculators, according to Clare, is because it has so much more to offer than the regular scientific ones. The operations that a graphing calculator can perform are much more advanced than the ones offered by a scientific calculator. Hence the keystroke sequence in order to execute the operation has to be learned correctly. 
Clare believes that students find learning math difficult enough without having confusion artificially created because different chapters in the same textbook are not consistent in the variables that are used to represent certain quantities. Clare tries to make it as easy as possible for her students to find connections between concepts they are learning, even if it means creating her own resources as opposed to using the textbook.

Clare firmly believes that technology should be used in the classroom as long as it aids in the learning process of mathematics. Clare will pick and choose through the curriculum materials and insert the use of the graphing calculator in a mathematics lesson where she believes it is the most appropriate. Clare believes that is it important that students construct their own knowledge of math and that the investigation will be more powerful if students are able to link the learning to a real world situation. Before each new investigation, Clare ensures that her students are prepared to use the graphing calculator.

\subsection{Self-Assessment}

The 24 questions in the self-assessment were taken from a Conceptions of Mathematics Inventory (Grouws, 1996). The 24 questions chosen from the inventory were divided into three groups that looked at three different conceptions of mathematical knowledge: the status of Mathematical Knowledge, doing Mathematics, and Learning Mathematics. The responses of the three teachers were categorized and a score was given to each of the three teachers for each of the three conceptions. "The Status of Mathematical Knowledge" questions attempt to determine whether the teacher conceives the state or nature of mathematics to be dynamic or static. The higher a teacher scores, the more dynamic that teacher believes mathematics to be. Each teacher's score was added up and divided by the number of questions that she answered. 
Victoria scored the highest, with a 5.00 out of a possible 6.00 , Dawn had the second highest score, 4.38 , and Clare was third, with a score of 3.88 . While there was a noticeable discrepancy in the scores, the responses of all three teachers suggest that they conceive mathematics to be a dynamic field. This conception is consistent with the observation that all three teachers appeared very willing to embrace the use of new technology in their classrooms, despite some of the challenges that they encountered when doing so.

The group of questions categorized as "Doing Mathematics" attempt to determine whether the teacher believes mathematics is about understanding and making sense of the concepts as opposed to being about knowing the correct procedure to use to reach the desired results. The higher the score calculated for each teacher, the more emphasis she believes should be placed on understanding the concept underlying the question, rather than on the mechanics of the question. Each teacher's score was added up and divided by the number of questions that she answered.

In this category, the three teachers' scores were more similar. Victoria scored the highest, with a 4.88 out of a possible 6.00 , Dawn was second, with a score of 4.50, and Clare scored 4.00. All three teachers' responses suggest that they believe that mathematics is about understanding concepts as opposed to being about knowing mechanical procedures.

The "Learning Mathematics" group of questions attempts to determine whether the teacher believes mathematics is learned through construction and understanding or through a process of memorization. The higher the score reached by a teacher, the more emphasis she believes should be placed on constructing learning rather than on memorization. Each teacher's score was added up and divided by the number of questions that she answered. 
For this group of questions, Victoria scored the highest, with 5.38 out of a possible 6.00, with Clare second this time, at 4.88, and Dawn third, with a result of 4.38. All three teachers' responses indicate that they conceive that mathematics is learned through construction and understanding rather than through a process of memorization.

Although there were discrepancies in the scores between the three teachers, the selfassessments suggest that all three teachers view mathematics as a dynamic field, emphasize understanding concepts as opposed to mechanical procedures, and prefer the construction and understanding of the concept to the memorization of procedures.

Among the three teachers, Victoria reported the strongest belief in each of the three conceptions. Dawn also reported fairly strong views on the three conceptions. Clare has less strong views on the first two conceptions than the other two teachers, although she reports fairly strong views on the third conception.

\subsection{Classroom Observations}

Comparing the self-assessment scores with the observations of the teachers when graphing calculators were present in their classrooms leads to several interesting findings. Victoria's students are proficient with the graphing calculators and so she never had to give them explicit button pressing instructions on how to perform an operation using their graphing calculators. Instead, Victoria was able to use the graphing calculators to focus her students' attention on the mathematical concepts and assist them in constructing their own understanding of mathematics.

Dawn's students use the graphing calculators much less frequently and are much less proficient in their use (although Dawn herself is very skilled at trouble-shooting difficulties that her students encounter when using the graphing calculators). Dawn had her students use the 
graphing calculators for graphing Linear and Quadratic Functions, along with investigating Linear Relationships. She encourages them to manipulate the Window settings on their calculators in order to explore these topics. Although Dawn has to spend a significant amount of time guiding her students to use more appropriate domain and range values, like Victoria, Dawn uses the graphing calculators to encourage her students to construct their own knowledge and understanding of mathematics.

Clare uses the graphing calculators in her classroom much more frequently than Dawn, although still much less often than Victoria. Clare must spend a lot of time reminding her students of the key strokes required to perform specific operations on their graphing calculators. Only after she has taught and reviewed the keystrokes could Clare proceed with exploring the mathematical concepts with her students. Nevertheless, Clare, like the other two teachers, appears to believe very strongly that the graphing calculator should be used as a classroom tool to help aid students in constructing their own understanding of mathematics.

The observations suggest that there were two factors that determined whether the teacher used the graphing calculators more for mechanical operations or more for constructivist examination of concepts. The first factor was the ease of accessibility to the graphing calculators and the corresponding comfort level the users had with them. The second factor was the mathematics topic that was being covered when the graphing calculators were being used.

With respect to the first factor, Victoria's students had constant access to graphing calculators because all students who participate in the IB program are required to purchase or rent one. As a result, Victoria expected her students to be proficient in the use of the graphing calculator. Instead of worrying about mechanical operations on the graphing calculators, Victoria 
was able to spend more time focusing her students' attention on constructing their mathematical knowledge and understanding.

Dawn and Clare spent less time using the graphing calculator in more constructivist roles because their students had limited access to graphing calculators. Each time the graphing calculators were brought into their classrooms, Dawn and Clare had to devote time to their students re-learning the correct button sequences to execute specific mechanical operations. Although the graphing calculators were used as springboards to constructive mathematical discourse once the solutions were achieved, Dawn and Clare had to spend most of their classroom time teaching students how to obtain these solutions on the graphing calculators.

For Victoria, the question of specific mathematical topics was not an issue because her students had access to the graphing calculators at all times. Victoria was therefore able to have her students use the graphing calculators at the most opportune moments at any time in the curriculum whenever she believed their use would support her students' constructive understanding of mathematics. Having constant access to graphing calculators means that Victoria can both plan for lessons involving the graphing calculators and also use them unplanned whenever an opportunity presents itself.

The mathematics topic that Dawn and Clare were covering in their classrooms was a significant determinant of whether they used graphing calculators to supplement their students' learning and understanding. Dawn and Clare only used the graphing calculators for those topics where they strongly believed the use of the graphing calculators would support and expand student understanding. Given that their students often spent the majority of classroom time learning the correct sequence of buttons to press to execute an operation, Dawn and Clare only used the graphing calculator for topics where they believed the time spent on these mechanical 
operations would significantly assist their students to construct their own understanding of the mathematical concepts underlying the topic.

\section{Discussion}

The study involved three teachers who each view mathematics as a dynamic field, emphasize understanding concepts as opposed to mechanical procedures, and prefer the construction and understanding of the concept over the memorization of procedures. All three teachers were willing to use graphing calculators in the mathematics classroom, and all three had a similar goal of attempting to use the graphing calculators to eliminate mechanical processing time and enhance their students' ability to construct their own learning.

This paper concludes that factors such as teachers' personal experiences and teaching practices, together with the level of proficiency of the students with the technology, influence how the graphing calculators are used in the mathematics classroom. The major findings of this paper, each of which is discussed in more detail below, relate to: (1) proficiency with the graphing calculator; (2) a common starting point; and (3) integration into the curriculum.

\subsection{Proficiency With The Graphing Calculator}

In order for students to focus on constructing their knowledge and understanding of mathematics, they cannot be hindered by calculation errors. Students that are proficient in the use of graphing calculators bypass cumbersome pencil and paper calculations and more easily reach the mathematical solution, enabling those students to focus on constructing their conceptual knowledge and solving more complex problems in mathematics (Drier et al., 1999; Dunham \& Dick, 1994; Ferrucci \& Carter, 2003; Forster et al., 2003; T. Graham at al., 2003; Heid \& Edwards, 2001). However, when students are not proficient in the use of graphing calculators, 
their struggles trying to determine the correct sequence of buttons to push on their graphing calculators result in the same hindrance the students faced with pencil and paper mechanics.

Dawn uses graphing calculators with her students at specific points in the curriculum. The graphing calculator was not a tool that was frequently used in her classes, so Dawn had to ensure that her students knew exactly which buttons they needed to push when executing an operation. Dawn would encourage her students to play around with the Window settings on their graphing calculators until they were able to see the linear function they were trying to graph. Clare also used the graphing calculators with her classes for specific topics. In order to ensure that her students could effectively deal with their graphing calculators, Clare had to recite the exact sequence of buttons that her students needed to press. Dawn and Clare both use the viewing screen to demonstrate what the students' should be seeing on their graphing calculator screens. This supports prior research findings (Graham, Headlam, Sharp and Watson, 2008) in which students were positive about the teacher's use of the viewing screen as an effective display tool.

With both Dawn and Clare, the graphing calculator is a tool that is brought into their classes at specific times. Their students do not have access to graphing calculators unless they are brought into the classroom and so specific units are planned around the use of the graphing calculators. In contrast, due to the requirements of the IB program, Victoria's students always have their graphing calculators with them. At any time, Victoria can ask her students to use their graphing calculators to check, find and evaluate their solutions. Victoria expects her students to be proficient using their graphing calculators. Unlike Dawn and Clare, Victoria does not use the viewing screen to show her students how to get an answer on their graphing calculators because her students are already familiar with the sequence of buttons that need to be pushed. 
Victoria's students are proficient at using their graphing calculators and thus the graphing calculators are used to demonstrate many different mathematical solutions. While Dawn and Clare's students must still concentrate on using the correct button pressing sequences to operate their graphing calculators, Victoria's students can concentrate on checking and interpreting their solutions. Dawn and Clare's students are still focused on the mechanics of operating graphing calculators, whereas Victoria's students can focus on constructing their mathematical knowledge and understanding because determining the solution is not an issue for them. These findings are again consistent with the findings of Graham et al (2008) in that students who are more familiar with the graphing calculator use it for a variety of purposes.

\subsection{A Common Starting Point}

The graphing calculator is a tool that can promote student discourse on mathematics solutions. Increasing student discourse in mathematics classrooms creates an opportunity for students to construct their own knowledge and understanding of mathematics (Draper, 2002; Drijvers \& Doorman, 1996; Watson \& Ciesla, 2006). Proficient use of the graphing calculator frees up students from mundane pencil and paper mechanics so that discussion can take place in the mathematics classroom about the concepts underlying the solution provided by the graphing calculator. Essentially, when mechanical operating issues are overcome, the graphing calculator provides students with a common starting point, which enables teachers to focus on discussion about mathematical concepts.

However, while students must be able to become proficient enough with mechanics to use their graphing calculators to reach an answer, the guidance and instruction provided by the teacher remains crucial for conceptual mathematical construction (Doerr \& Zangor, 2000;

Ferrucci \& Carter, 2003). With the graphing calculator, Dawn is able to illustrate linear functions 
using real-world examples, such as determining the best place to hold graduation or the best place to work. Dawn uses these real-world examples to hook the interest of her students and give them a scenario that they can relate to and thus claim ownership of. If Dawn's students were to attempt to graph a real-world example using pencil and paper methods, many of them may become hindered as they attempt to determine an adequate domain and range for the $\mathrm{x}$ - and $\mathrm{y}$ axes. Creating graphs where the axes need to be completely altered because of inadequate increments may use up all the time allocated to the lesson. Instead, the combination of receiving directed instruction from their teacher and the ease of changing Window settings on the graphing calculator means that Dawn's students can easily change parameters for their real-world example and have immediate visual access to the problem they are investigating.

For Clare's students, the correct sinusoidal graph offers her class the starting point necessary for a real-world example. Clare connects the exercise on graphing a sinusoidal function to the timing of the tides in the Maritimes. Clare is able to connect her students' abstract learning of sinusoidal functions to a real life application. Using the graphing calculator enables all of Clare's students to quickly and efficiently produce the same graph. This common starting point, together with Clare's guidance, generates mathematical discourse in Clare's classroom that allows her students to construct their conceptual understanding around something tangible in the real-world, making it more meaningful to them.

Although the use of the graphing calculator is not as obvious a springboard for mathematical discourse in Victoria's classroom as it is in the classrooms of Dawn and Clare, the net effect is the same. With Victoria's students, since they always have access to a graphing calculator and tend to be proficient in its use, getting the correct answer to a graphing question is taken as a given. As a result, what the students are required to do with the solution is more 
important, together with how the solution is to be interpreted. The types of IB questions Victoria's students are given require them to use the graphing calculator not just to reach an answer but also to explain what the answer means in a given contextual framework.

\subsection{Integration Into The Curriculum}

Dawn, Clare and Victoria all have access to resources that illustrate where technology like the graphing calculator can be used to supplement the curriculum. However, all three teachers determine for themselves the most appropriate places in the curriculum to bring in the graphing calculator.

Just like teaching examples need to be meaningful to students, the graphing calculator resources need to be meaningful to the teachers if they are to use them. For example, Clare mentions that she will not use the graphing calculator to illustrate a table of values just because the textbook uses it for that purpose. She explains that this is because she does not believe that simply inputting the values in the graphing calculator will add anything to her students' understanding of the mathematics. In Dawn's case, although she has not been supplied with any resources for this, she uses the graphing calculator when she is teaching her students how to draw linear equations because she believes that the graphing calculator adds speed and efficiency that will better enable her students to construct connections with the real world. For Victoria and her students, pre-determining where in the curriculum the graphing calculators fit most appropriately is not an issue because they have access to graphing calculators all the time.

Given their limited access to graphing calculators, Dawn and Clare determine the most appropriate places to bring in the use of the graphing calculators based on when they believe that the use of the graphing calculators will best help their students construct the mathematical knowledge and understanding they need at specific points in the curriculum. Given this role for 
teacher belief, it is important that the benefits of using graphing calculators in different parts of the curriculum be explained to teachers. Teachers must then develop their own rationales for implementing the use of graphing calculators in their own classrooms in a manner that makes the use of graphing calculators meaningful for the students.

\section{Conclusion}

The major findings of this paper relate to: (1) proficiency with the graphing calculator; (2) a common starting point; and (3) integration into the curriculum. Teachers who are more experienced professionally and personally with the use of technology are in a better position to welcome the use of technology in their classroom. Teachers who are proficient in using the graphing calculators can in turn teach their students to effectively and efficiently use their graphing calculators. Proficient use of the graphing calculator frees up students from mundane

pencil and paper mechanics so that discussion can take place in the mathematics classroom about the concepts underlying the solution provided by the graphing calculator. Essentially, when mechanical operating issues are overcome, the graphing calculator provides students with a common starting point, which enables teachers to focus on discussion about mathematical concepts. Teachers will determine for themselves where in the curriculum are the most appropriate places to incorporate the use of graphing calculators.

The use of technology must be meaningful in order for students and teachers to continue to use tools like the graphing calculator in mathematics classrooms. When graphing calculators are used effectively in the mathematics classroom, they are a powerful tool to assist teachers in providing their students with an environment to help them construct their mathematical knowledge and understanding. 


\section{References}

Arbaugh, F. (2003). Study groups: Professional growth through collaboration. Mathematics Teacher, 96(3), 188-191.

Cates, J. M. (2002). Understanding algebra through graphing calculators. Learning \& Leading with Technology, 33-35.

Cradler, J., Freeman, M., Cradler, R., \& McNabb, M. (2002). Research implications for preparing teachers to use technology. Learning \& Leading with Technology, 30(1), 50-54

Doerr, H. M., \& Zangor, R. (2000). Creating meaning for and with the graphing calculator. Educational Studies in Mathematics, 41, 143-163.

Draper, R. J. (2002). School mathematics reform, constructivism, and literacy: A case for literacy instruction in the reform-oriented math classroom. Journal of Adolescent and Adult Literacy, 45(6), 520-529.

Drier, H. S., Dawson, K. M., \& Garofalo, J. (1999). Not your typical math class. Educational Leadership, 21-25.

Drijvers, P., \& Doorman, M. (1996). The graphics calculator in mathematics education. Journal of Mathematical Behavior, 15, 425-440.

Dunham, P. H., \& Dick, T. P. (1994). Research on graphing calculators. The Mathematics Teacher, 87(6), 440-445.

Ferrucci, B. J., \& Carter, J. A. (2003). Technology-active mathematical modelling. International Journal of Mathematical Education in Science and Technology, 34(5), 663-670.

Forster, P. A., Mueller, U., Haimes, D., \& Malone, J. (2003). Impact on school assessment where use of graphics calculators is mandatory in a related public examination. International Journal of Mathematical Education in Science and Technology, 34(3), 343-359.

Graham, A. (1999). Statistical nuggets with a graphics calculator. Teaching Statistics, 21(3), 7073.

Graham, T., Headlam, C., Honey, S., Sharp, J., \& Smith, A. (2003). The use of graphics calculators by students in an examination: What do they really do? International Journal of Mathematical Education in Science and Technology, 34(3), 319-334.

Graham, E., Headlam, C., Sharp, J., \& Watson, B. (2008). An investigation into whether student use of graphics calculators matches their teacher's expectations. International Journal of Mathematical Education in Science and Technology, 39(2),179-196.

Grouws, D. (1996). Student conceptions of mathematics: A comparison of mathematically talented students and typical high school algebra students. Proceedings from a paper presented at the Annual Meeting of the American Educational Association 1996:

Heid, K. (1988). Calculators on tests - one giant step for mathematics education. Mathematics Teacher, 81(9), 710-713.

Heid, K., \& Edwards, M. T. (2001). Computer algebra systems: Revolution or retrofit for today's mathematics classrooms? Theory into Practice, 40(2), 128-136.

Iossif, G. (1999). The graphics calculator as a teaching aid in statistics. Teaching Statistics, 21(2), 45-48.

McDougall, D. E. (1997). Mathematics Teachers' Needs in Dynamic Geometric Computer Environments: In Search of Control. Unpublished Doctor of Education, University of Toronto, Toronto.

Moersch, C. (2002). Measurers of success: Six instruments to assess teachers' use of technology. Learning \& Leading with Technology, 30(3), 10-13. 
National Council of Teachers of Mathematics. (2000). Principles \& Standards for School Mathematics, from http://standards.nctm.org/document/index.htm

Philipp, R. A., Flores, A., Showder, J. T., \& Schappelle, B. P. (1994). Conceptions and practices of extraordinary mathematics teachers. Journal of Mathematical Behavior, 13(2), 155180.

QSR. (2002). N6 (Non-numerical Unstructured Data Indexing Searching \& Theorizing) (Version $6)$.

Quesada, A. R., \& Maxwell, M. E. (1994). The effects of using graphing calculators to enhance college students' performance in precalculus. Educational Studies in Mathematics, 27, 205-215.

Skemp, R. R. (1978). Relational understanding and instrumental understanding. Arithmetic Teacher, 26(3), 9-15.

Stipek, D. J., Givvin, K. B., Salmon, J. M., \& MacGyvers, V. (2001). Teachers' beliefs and practices related to mathematics instruction. Teaching and Teacher Education, 17, 213226.

Watson, J. W., \& Ciesla, B. A. (2006). Finding complex roots: Can you trust your calculator? Mathematics Teacher, 99(5), 366-371. 